\title{
CHILDREN AND ADULTS IN SECOND-LANGUAGE LEARNING
}

\author{
Hadna Suryantari \\ SMA Muhammadiyah Pleret, Bantul, Yogyakarta,imhadnaa93@gmail.com
}

\begin{abstract}
Learning is a process in which people study to acquire or obtain knowledge or skill. Second language learning is a process of internalizing and making sense of a second language after one has an established first language. Learning a second language is different from learning first language. Second language is learnt after one is able to speak and has absorbed knowledge, which influences him in learning a second language. Most of us believe that children are better than adults in learning second language. This statement is supported by common observation stated that young second-language learners seems to be able to learn another language quickly by exposure without teaching. In this article, the writer tries to present how children and adults in second-language learning based on factors involved in it. Steinberg (2001) states that there are three factors involved in second-language learning. The first is psychological category. It includes intellectual processing which consists of explication and induction process, memory, and motor skills. Then, social situation consists of natural situation and classroom situation. The last is other psychological variables. It consists of ESL or EFL community context, motivation, and attitude. It is complex to determine whether children or adults are better in second-language learning. The common belief that children are better than adults has been proved, although with some qualification regarding the classroom situation. Put another way, adults do not do best in any situation. In the natural situation of language learning, it is determined that young children will do better than adults, and so will older children. It is not even uncommon for young children to learn a second language in a year or less. Therefore, children do better than adults. In the classroom situation, older children will do better than adults. However, young adults will do better than young children to the extent that the young children's classroom is not a simulation of the natural situation. In the simulation case, young children will do better.
\end{abstract}

Keywords: learning, SLA, psychological factors, social factors, other influences

Learning is a process in which people study to acquire or obtain knowledge or skill. Second Language Acquisition (SLA) refers to the process of learning another language after the native language has been learned. Second language learning is a process of internalizing and making sense of a second language after one has an established first language. Many people think that second language learning is the same as second language acquisition. In fact, it differs in some ways. Krashen (2002) defines learning as a process between acquiring and utterance. It can be said that language acquisition happens in subconscious system, while language learning happens in conscious system. Learning a second language is different from learning first language. Learning first language has been started since one is just a baby who does not have the ability to speak and only able to deliver messages by babbling, cooing, and crying. However, second language is learnt after one is able to speak and has absorbed knowledge, which influences him/ her in learning a second language.

Most of us believe that children are better than adults in learning second language. This statement is supported by common observation stated that young second-language learners seems to be able to learn another language quickly by exposure without teaching. Steinberg (2001) states that there are some factors involved in second-language. These factors are divided into three categories: (1) psychological, (2) social situation, and (3) other psychological variables.

Steinberg (2001) considers three main points of psychological category. The first is intellectual processing which is involved in an individual's analytical determination of grammatical structures and rules. Then, it is memory which is important if language learning occurs and remains. The last is motor skills which relate to the sounds of pronunciation involved in the second language.

The second category is social situation. It is said as types of situation, setting, and interactions that can affect the learning of second language learning. This category is related to where and with whom the 
second language exposure happens. Therefore, the discussion will be focused on the natural situation and classroom situation.

The last category is other psychological variables. It is related to the effect of other individual factors that can affect second language learning. Therefore, the discussion will be focused on language community context, motivation, and attitude in learning second language.

In this article, the writer tries to present how children and adults in second-language learning based on factors involved in it including psychological factors, social situation factors, and other psychological variables.

\section{Basic Psychological Factors Affecting Second Language Learning}

\section{Intellectual Processing: Explication and Induction}

Intellectual processing discusses about the ways to learn syntax of second language. According to Steinberg (2001) it can be explained by someone to us which is called as explication or it can be understood by our self which is called as induction.

\section{Explication}

Explication is the process of the rules and structures of second language explained to a learner. The explanation is given in the learner's first language. Then, the learner is expected to understand, learn, and apply the rule in second language. The explication is not given in second language because the learner has no know enough that language yet. It can only be given in second language for very well advanced second language learners.

Staats (1993) states that explication is rarely done by parents or other children acquire a native language, but 4 or 5 native children can understand and speak most of their native language quite well. They have learned language by self-analysis, called as induction. Parents do not attempt to explain structure and grammar to their children like a simple morpheme rule as plural and subject-verb agreement in a sentence. Even if parents are able to formulate the explanation, they know that their children would not be able to understand it.

The explanation above means that the ability of explication increases with age. Children in age of fewer than 7 years have great problems in understanding about a second language.

$2 . \quad$ Induction

Herschensohn (2007) states that induction is learning rules by self-discovery children who are exposed to second-language speech and remember what they have heard will be able to analyze and discover the rules underlie the speech. With the rules, the learners are in process to be able to use and understand the more complicated rules. Such phenomena as pronominalization, negation, and the plural are learned by induction become part of a young native speaker's language knowledge quite early, long before the child enters school.

Dornyei (2009) states that the second language will always trying to understand language by induction. This is simple and natural thing to do. So long as the structures involved are not far beyond the learners' syntactic level understanding, there is a good chance that the learner can discover the rules by self-analysis.

Based on the explanation above, we can see that insofar as induction is concerned, this ability remains at a relatively high level with age, except with certain individuals in old age. This ability allows us to make new discoveries in our everyday life, even to the extent of being able to analyze the syntactic structures of a second language.

a.Memory

Memory is important to learning. It is inconceivable that people with severe memory impairment can ever learn their native language, much less a second language. The learning simplest words require memory. The greater the number of related occurrence needed for learning, the poorer is someone's memory. It is why second-language learners and teachers are always talking of practice and review. It is needed because of lack in memory ability. 
1. Children's Memory Ability

The memory ability of very young children seems to be unparalleled in that they can absorb a phenomenal amount of data. While children at the age of 5 or 6 still display a phenomenal ability at rote memorization, it seems that older children do not, with some decline beginning around 8 years of age and with more of a declining from about 12 years age. It seems that children's ages can be usefully divided into two categories, under 7 years and 7 to 12 years.

It seems that younger children tend to rely more on memory than older children. Harley and Dough (1997) stated that older children begin to apply their cognitive abilities in analyzing the syntactic rules of the second language while younger children relied more heavily on their use of rote memory for language learning. It can be interpreted that older children jump to syntactic sooner because they realize that they have difficulty in remembering all of the sentences which they hear.

$2 . \quad$ Adult and Children in short-term memory tasks

In other types of memory tasks, adults may have the upper hand. According to Hunter (1964) shortterm memory seems to increase up to the age of 15 . However, further research demonstrated that rehearsal strategies are more likely to the cause of the greater adult short-term memory since adults are better in understanding how to go remembering. Children seems not to realizes that memory has limits and are less able to decide on the level of importance of what is to be remembered. It shows that children are likely to persevere on meaningless task than adults and that these tests may not have measured memory as it is used by children in language learning.

Cook (1977) found that when adults are able to apply their more developed memory, as in many classroom learning situations, they perform better than children, but when they cannot, they perform at a level similar to that of children. Thus given adequate time to devise memory strategies, adults may outperform children on some language tasks. However, whether this would suffice for the learning of an entire language is doubtful.

3. Sharp decline of memory

Memory seems to begin its sharpest decline around the age of puberty. Undoubtedly this is due to some change in the brain. Typically, second-language learning becomes more difficult for the 15- or $20-$ years - old than 5 - or 10 - years old. In the normally aging of brain, previously acquired long-term memories seem relatively unaffected; one's knowledge of the world which is built up over decades is not forgotten and remains intact (Salthouse, 1982). It is in the acquisition of new learning, particularly language learning, where problems occur. The change in ability for the older adult can be explained as a deficit in linguistic processing rather than a problem with memory. Since adults continue to engage in higher thinking and analysis well beyond their forties and fifties, there is little reason to believe that they would not be able to analyze syntactic structures. The decline in memory ability is the more likely hypothesis. Having to remember sentences and situations and then the analyses which are assigned those sentences, even when such data are presented in classroom situation, becomes more difficult with age.

Based on the explanation above, It can be said that memory ability of under 7 years children is in high level. Such ability, memory ability declines with age. Therefore as old we are, as decrease our memory ability.

\section{Motor Skills}

Good pronunciation is an important part in learning a foreign language. The better our pronunciation, the better we can communicate with others. The creation of speech sounds is related to the ability to control the muscles which manipulate the speech organs. Motor Skills is a term which psychologist use to describe the use of muscles in performing certain skills from the general like walking, writing, and speaking.

The motor skills which are involved in speech utilize what linguists call the articulator of speech. These include the mouth, lips, tongue, vocal cords, etc which are controlled by muscles which are under the general control of the brain. The articulators of speech have to do the right thing at the right time like opening the mouth in a certain way and positioning the lips and tongue in certain way to utter sounds accurately. 
1. Decline in General Motor Skills

Around the age of 12 years or so, there is a general change throughout our body that affects all of our motor skills. Most persons experience a decline. The reason for the decline in the fine control of the muscles of the body is yet unknown, although, since the decline is such a general nature, involving all parts of the body, it seems likely to be due to some change in central functioning in the brain. Hormonal changes prior to puberty may have something to do with this but this is only speculation on our part. (Snow and Hoefnagel-Hoehle, 1977).

$2 . \quad$ Decline in Ability for New Articulations

As we age and as our ability to acquire new mot skills declines, our ability to command our articulators of speech is affected negatively. It can be expected that children do much better in the pronunciation of second language than adults because children have flexibility in motor skills which adults generally have lost.

The earlier the age at which acquisition of the second language begins, the more native-like the accent will be. Oyama (1976) did a study of Italian immigrants. It showed that the younger children the children, the more native-like would be their pronunciation. The subjects were 60 Italian-born male immigrants who lived in the greater New York metropolitan area. The subjects were categorized according to age at arrival in the United States' (6 to 20 years) and number of years in the United States (5 to 20 years). It was found that the younger arrivals performed with near-native English pronunciation while those who arrived after about the age of 12 years had substantial accents. Length of stay had little effect. Oyama's study related to pronunciation proficiency means that it is difficult for adults to achieve nativespeaker pronunciation.

There is a more reason why a foreign accent might persist in a second language. One's ability to hear foreign speech sound accurately may be involved. If one hears sounds solely through the filter of the first language, one may not be aware of a need for correction.

\section{Social Situation Affecting Second-Language Learning}

There are many social situations in second-language learning. Steinberg (2001) states that basically, the social situation is divided into two important categories. Those are natural situation and classroom situation. The natural situation is situation where second language is learned in situation which similar to the first language is learned such as family, play, and workplace. Meanwhile, classroom situation involves the social situation of the school classroom.

\section{a. The Natural Situation}

A natural situation for second-language learning is one where the second-language is experienced in a situation that is similar to the native language is learned. Steinberg (2001) states that children can learn second language faster than adults in natural situation. However, the reason why adults cannot be better than children is uncertain, it is caused by the declining memory and motor skills factors or not.

1. Decline of Beneficial Social Interaction with age

Herschensohn (2007) states that generally, as one gets older there is decline in the kind of social interaction which promotes language learning. Adults' second-language learners have fewer good opportunities in a new language community than children. If adults spend much their time to stay at home, they will not be able to meet and talk much to the native speakers. Social language interactions in the workplace can be very limiting. It is caused by the lack of second-language ability, adult learners will not be hired to do work that required native speakers to linguistically interact with them in any depth, whether their work allowed them to use their native language. It is almost impossible to imagine a situation in which adults will be continually exposed to the same good quality and quantity of language that a child receives.

2. With age, language is more important for social interaction 
It is important to note for adults that social interaction happens through language. Preston (1989) states that few native speaker adults are willing to devote time to interact with someone who does not speak the language, with the result that the adult foreigner will have little opportunity to engage in meaningful and extended language exchanges. In contrast, the young child is often readily accepted by other children, even adults. For young children, language is not important to social interaction. It is called as 'parallel play'. They can be content just to sit in each other's company speaking only occasionally and playing on their own. Older children can play games. Adults rarely find themselves in situations where language does not play important role in social interaction.

3. Older children' problem

The greater the role a language plays in social interaction and the more the person may experience difficulty in being accepted. Peer-group acceptance becomes a greater problem, especially around the age of puberty. Without social acceptance, second language learning in natural situation can hardly begin for a learner. Sometimes older children may not want to identify with a new community and will consequently resist learning the new language (Preston, 1989). It is caused by children have not yet developed their own identities. They may be more accepting of the social norms of a new community. Therefore, the younger children will be more likely to accept learning a new language.

b. The Classroom Situation

1. The classroom is isolated from other social life

The classroom for second-language learning is a planned situation. There is an isolated room from the social life. In the room there is a teacher and a number of students. The teacher is the one who knows the second language and the students are there to learn the language. In the space of the classroom, nothing happens unless the teacher makes it happen. In the classroom students do not act as they want. They should follow the directions from the teacher. All activity is related to language learning. It is very different from their home or community where they can walk around doing things.

2. $\quad$ Everything is planned, little is spontaneous

In the natural situation, language is one of life aspect which accompanies other life events. However, language in the classroom becomes the main aspect. The language is experienced by the students and the activities which are done and planned by the teacher. While there are degrees of planning with more or less emphasis on speech, literacy, spontaneity, etc. In this isolated room, the teacher is the prime source of the second-language and planning is a must. This is true even for methods which attempt to simulate the natural situation by reproducing in the classroom some of the natural language experience which occur outside the classroom. Exposure to good native speech, role playing, and games are some of the devices employed to allow for the natural self-discovery of language and its use. Still, it is the teacher who plans and controls such activities. (Ellis, 1992).

3. $\quad$ Learning language as part of a group and not as andividual

There are other characteristics of the planned classroom situation which distinguish it from the natural situation. These include social adjustment to group process, the need to attend class in order to learn, the need of long periods of concentration, and required doing homework at home.

The explicit teaching of grammatical structures and rules may be involved, depending on the method used. Using books and taking notes are often expected of the students. Students have to get used to learning language as an academic subject. Thus, when considering overall demands of the classroom situation, it is clear that the older one is, the better one is able to adjust and function within that situation. Young children often will not do as well as older children and adults.

\title{
Some other Influences in Second-Language Learning
}

\author{
Language Community Context: English as a Second Language (ESL) or English as a Foreign \\ Language (EFL)
}


According to Fathmann (1978) ESL context provides more language-learning opportunities for the second-language learner through exposure to natural situations outside the classroom, such learners, unsurprisingly, will generally progress more rapidly than learners living in an EFL context. Furthermore, the ESL context will benefit children more than it will adult. Of course, the ESL context will benefit adult too, but to a lesser degree. Conversely, adults can do better in the EFL context where they can apply their superior cognitive skills for learning in the classroom situation.

a. Motivation

Brown (1980) stated that language learning will be more success if there is certain motivation inside the learner. Steinberg (2001) stated that a 1- or 2-years-old needs no motivation to learn a secondlanguage. An older child of 4 or 5 years may need motivation, since by that age the child may be aware of whether a language is positively or negatively regarded by others. Older children may also have more various motivations in their L2 learning. To adults, according to Gardner and Lambert (1972) in Cook (2008), there are two kinds of motivations in second-language learning. Those are

(1) Integrative Motivation is defined as the desire to be like valued members of community that speak the second language or just be able to communicate with L2 society. The presence of integrative motivation should encourage the acquirer to interact with speakers of the second language out of sheer interest, and thereby obtain intake.

(2) Instrumental Motivation, it is defined as the desire to achieve proficiency in a language in order to get benefits like acquired to get a job. Its presence will encourage performers to interact with L2 speakers in order to achieve certain ends. For the instrumentally motivated performer, interaction always has some practical purposes.

\section{b. Attitude}

Gardner \& Lambert (1985) stated that a negative attitude toward the target language or its speaker, or other members of the class, may also affect one's determination and persistence to be involved in the classroom and its activities. According to Brown (1980) the same negative attitude could impair memory functioning and detract from focusing on the target language. In the same way, any of host of personality and social cultural variables could have deleterious effect.

Steinberg (2001) stated that attitude may not play a role in the natural situation. By 4 years of age children have developed attitudes towards language. They know how people react to different languages. For example, children may not wish to use their native, but foreign, language outside of home. They prefer to conform to their peers and other members of the dominant language community.

\section{Who is Better between Children and Adults in Second-Language Learning}

Based on the explanation of psychological and social factors affecting children and adults in secondlanguage learning above, Steinberg (2001) draws the comparison factors affecting second-language learning between children and adults into the following table: 
Table 1. Psychological Factors and Social Factors Affecting Second-Language Learning for Children and Adult

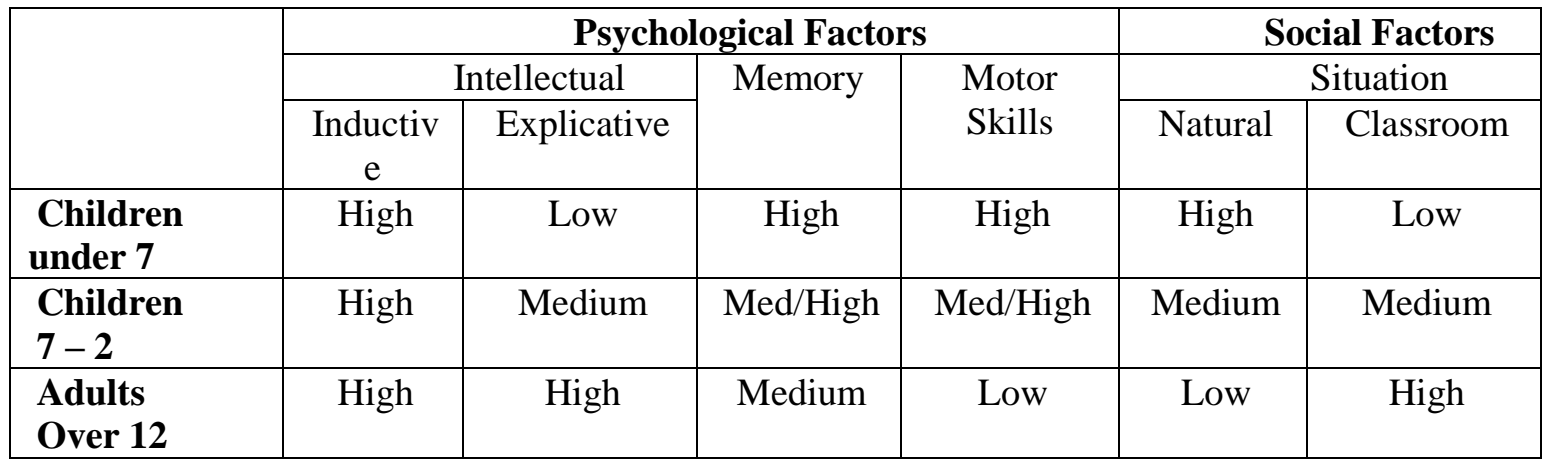

Based on the table above, children will do best in natural situation. They have high on natural situation and inductive. Explicative is not appropriate because natural situation learning is through induction not explication. There are also high on memory and motor skills.

Adults have a low on natural situation and a high on inductive and explicative intellectual learning. However, high on induction does not help in learning syntax. It is cause by the adult learners do not enough appropriate language and non-language data for analysis through the natural situation. Explication is not appropriate to the natural situation because rarely will people be able to explain grammatical points in the learner's native language. Based on this fact, adults have medium on memory and low on motor skills. While, Older children would do better than adults because they are medium on natural situation and medium to high on memory and motor skills.

The natural situation is better for children. It is caused by adults undergo a marked decline in the quality and quantity of social interaction to good language learning. There is no question that, in a natural situation, the social activities of children, especially young children, expose them to massive amounts of good, natural language. This does not occur for adults, and in many cases, not even for older children. In extreme cases, members of these groups may even find themselves in social conditions which are hostile condition which discourage over the adult.

Psychologically, Dornyei (2009) states that children and adults have optimal power on induction and they are able to induce the grammar of a second language more or less equally well, nonetheless, it will be easier for children to learn syntax than it will be for adults. This is because adults undergo a decline in memory without remembering the data, there is nothing to analyze. Adults and even older children lose the formidable powers of rote learning that young children have. Although adults may devise memory strategies and can seek out more practice, nevertheless, this place an additional burden on them, one that the child does not have. Therefore, children, especially younger children, will have an advantage over adults in learning the syntax of a second language.

For the same reason, older children can be expected to learn faster than adults because of better memory. However, because adults seem to be superior at employing strategies that assist them in learning, adults generally may initially learn at a faster rate. A tent-month study conducted by Snow and HoefnagelHohle (1978) found that in the beginning, adolescents were superior to both adult and children on test of morphology and syntax, and that adults even performed at a higher rate than children. However, with time, the children caught up and overtook the other groups.

In the classroom situation, adults will do better than young children. Adults are not only better in explicative processing but also they know how to be students. They have sufficient maturity to meet the rigorous of a formal learning environment, where concentration, attention, and ability to sit for a long time, all play a role in learning.

Because the older child's memory and motor skills are better than the adult's, the advantage in explicative processing enjoyed by the adult may not be sufficient to overcome the disadvantages experienced in these areas. Thus, the older child will probably do better than the adult in the classroom situation. The best age to learn a second language in the typical explication classroom situation is probably 
that age where the individual retains much of the memory and motor skills of the very young, but where the individual has begun to reason and understand like an adult. That age would probably be somewhere around 10 years.

\section{Conclusion}

Based on the explanations above, it is complex to determine whether children or adults are better in second-language learning. The common belief that children are better than adults has been proved, although with some qualification regarding the classroom situation. Put another way, adults do not do best in any situation.

In the natural situation of language learning, it is determined that young children (under 7 years) will do better than adults, and so will older children (between $7-12$ years). It is not even uncommon for young children to learn a second language in a year or less. Therefore, children do better than adults.

In the classroom situation, older children will do better than adults. However, young adults will do better than young children to the extent that the young children's classroom is not a simulation of the natural situation. In the simulation case, young children will do better.

\section{References}

Brown, Douglas, H. (1980). Principle of Language Learning and Teaching. New Jersey: Prentice Hall Inc.

Cook, Vivian. (2008) Second Language Learning and Language Teaching. London: Hodder Education.

Dornyei, Zoltan. (2009). The Psychology of Second Language Aqcuisition. New York: Oxford University Press.

Ellis, Rod. (1992). Second Language Acquisition and Language Pedagogy. Adelaide: Multilingual Matters.

Fathmann, A. (1978). ESL and EFL Learning: Similar or Dissimilar? In C. Blatchford \& J. Schachter (eds), On TESOL (pp. 213 - 23). Washington, DC: TESOL.

Gardner, R. A.(1985). Social Psychology and Second Language Learning: The Role of Attitudes and Motivation. London: Edward Arnold.

Harley, B., \& Dough, H. (1997). Language aptitude and second language proficiency in classroom learners of different starting ages. Studies in Second Language Acquisition, 19I3, 379 - 400.

Herschensohn, Julia. (2007). Language Development and Age. United States of America: Cambridge University Press.

Krashen, Stephen D. (1981). Second Language Acquisition and Second Language Learning. Oxford: Pergamon Press Ltd.

Krashen, Stephen D. (2002). Second Language Acquisition and Second Language Learning. California: Pergamon Press.

Oyama, S. (1975). The sensitive period for the acquisition of a non-native phonological system. Journal of Psycholinguistics Research, 5, 261-85.

Preston, D. (1989). Sociolinguistics and Second Language Acquisition. Oxford: Blackwell. 
Salthouse, T. A. (1982). Adult Cognition: an experimental pedagogy of human aging. New York: Springer - Verlag.

Snow, C., \& Hoefnagel - Hohle, M. (1978). The critical age for language acquisition: evidence from second-language learning. Child Development, 49, $1114-28$.

Staats, A. (1993). The study of cognitive process in second language learning. Applied Linguistics, 2, 117 31.

Steinberg, D. D.,Nagata, H., \& Aline D. P. (2001). Psycholinguistics: Language, Mind, and World. Malaysia: Pearson Education. 